\title{
CALORIFIC VALUE DETERMINATION OF SOLID BIOMASS FUEL BY SIMPLIFIED METHOD
}

\author{
Giuseppe Toscano, Ester Foppa Pedretti
}

\section{Introduction}

The whole process of thermal utilization of solid biofuels (fuel supply, combustion system, solid and gaseous emissions) is influenced by the kind of solid biofuel used, its physical characteristics (e.g. particle size, bulk density, moisture content, calorific value) and its chemical composition [Obernberger 2006]. These parameters are fundamental for the definition of the commercial value of the materials [Fernandez Llorente 2008], for the measurement and the evaluation of the plant efficiency, and the judgment of the technical-economic convenience of a process. For these purposes, the calorific value should represent the most important characteristic for the establishing the price of the solid biomass.

The parameter that is necessary for the definition of the energetic content of the materials is the gross calorific value $(G C V)$ or high heating value. It represents the absolute value of the specific energy of combustion, in joules, for unit mass of a solid biofuel burned in oxygen in a calorimetric bomb under the conditions specified [CEN/TS 14918:2005]. On the basis of the $G C V$ and the elemental composition, the net calorific value $(N C V)$ is calculated. CEN/TS 14918 defines $N C V$ at a constant pressure as the absolute value of the specific heat (enthalpy) of combustion, in joules, for unit mass of the biofuel burned in oxygen at constant pressure under such conditions that all the water of the reaction products remains as water vapour (at $0.1 \mathrm{MPa}$ ), the other products being as for the gross calorific value, all at the reference temperature. The $N C V$ expresses the actual energetic content of combustible with respect to a precise humidity value.

The calculation of $G C V$, measured in a bomb calorimeter, is particularly important for the solid bio-

Paper received 14.07.2008; accepted 30.04.2009

Dott. GIUSEPPE ToscAno, researcher, Dept. SAIFET, Technical University of Marche, g.toscano@univpm.it

Prof. Ester FopPa PedRetTI, associate professor, Dept. SAIFET. Technical University of Marche, e.foppa@univpm.it fuels since they generally have high variability in their chemical-physical composition. Nevertheless, in many applications it may not be easy to measure the $G C V$. The measurement is complicated and is a timeconsuming process that requires set-up, measurement and calculation procedures.

In the absence of calorimetric data, the $G C V$ of a solid biomass may be estimated by the element composition [Meraza 2002; Meraza 2003]. The conventional analysis, i.e. proximate and ultimate analyses (or elemental analysis), is a basic fuel characterization and can be carried out more easily, quickly, and cheaply by using common or modern laboratory equipments [Sheng 2005]. Numerous empirical equations have been published to relate the heating value of fuel to the its element composition of fuel as obtained by the element analysis [Meraza 2003; Gharagheiz 2008; Friedl 2005; Thipkhunthoda 2005; Demirbas 1997]. Nevertheless, fewer correlations have been developed on biomass. There are numerous correlations to calculate $G C V$ from the element composition of fuel, most of which have been derived from coal [Parikha 2005; Channiwala 2002]. Many correlations derive from the Dulong correlation, exclusively based on the percentage content of hydrogen $(H)$, carbon $(C)$ and oxygen $(O)$. Other elements that constitute solid biomass were considered in other correlations: nitrogen $(N)$, sulphur $(S)$ and ash content.

The correlations available in the literature are reported with high accuracy applied to the investigator's own database. An extrapolation to various biomass species, however, leads to considerable differences among the calculated results of the correlations. As a result, it would be very confusing for engineers to make their own selection [Sheng 2005]. It can be assumed that it is similar to the generalized extension of the correlation with various types of combustibles, including biomasses, available in literature, and that it does not envisage the different chemical complexity of the materials and its impact on the energetic content. For example, wooden materials have different cellulose, hemicelluloses and lignin compositions [Giordano 1971] while some biomasses can even contain variable fractions of fat. 
The $G C V$ of a lignocelluloses fuel is a function of its lignin content. In general, the $G C V$ of lignocelluloses fuels increases with the increase of their lignin contents and the $G C V$ is highly correlated with lignin content. Again the heat content is affected by the proportion of combustible organic components (called extractives) present in it [Demirbas 2001].

A general evaluation of the correlations found in literature highlights how the accuracy of the correlations based on the proximate analysis data are very low since the analysis provides only the empirical composition of biomass [Sheng 2005]. The formulae based on the ultimate analysis are generally more accurate than those based on proximate analysis. The quality of the correlations based on chemical analysis was found to be very poor because of the variation of the biomass components properties as well as the biomass chemical composition. The regression coefficients of all the correlations, including the proposed ones, are less than 0.85 . This shows the effect of variations in the biomass components [Meraza 2003]. Moreover, in various studies, it has been found that the data used to calculate the correlations were not measured directly by the author but deduced from other literature and other sources with a probable increase of errors.

At the Polytechnic University of the Marche Region, Ancona, there is a research lab on biomass for energetic use (Biomass Lab) which carries out various chemical-physical analyses on various types of materials. Given the high availability of analysis data, conducted with the same methods and tools, it has been considered useful to test the performance of some $G C V$ measurement models defined in literature or deduced from the statistical analysis of available data. Additionally, aim of this study was the development of simplified model for the determination of $G C V$ and $N C V$ values through analytical correlations contained few parameters.

\section{Material and methods}

For this study the data from the analysis of 451 samples of biomasses of different types and origins was used. The chemical-physical analyses on materials were carried out according to the methodologies described in CEN technical normative for solid biomass. The data from the analysis are archived in a database to facilitate the organization of specific research and data processing.

The study procedure used on the biomass samples involves an initial preparation phase of the latter in compliance with CEN/TS 14780 and then specific physical-chemical analysis will be carried out on them. Within this study, the following parameters were recorded: ash content dry basis $\left(A_{C}\right)$, gross calorific value dry basis $(G C V)$ and the element composition $(C, H, N, S$ and $O)$. As for the $G C V$ and the element analysis the value of the net calorific value on dry basis $N C V$ was calculated. Table 1 summarizes the methodologies used and the main summary information of the analytic parameters measured in this study. The analyzed samples are represented by lignin-cellulose type of materials of which $50 \%$ is made of pellets and chips, generally produced from waste from wood or forests and the remaining part from agriculture by-products (straw, fruit plan cuttings, waste from cultivation harvesting, etc.) or waste from agro-industrial processes (olive and grape cake, sunflower cake, husks, etc).

For the data processing, the database was sub-divided into two distinct parts. The first part of the database, - database for calculations $\left(D B_{c}\right)$ - made up of data from 200 samples, was used to calculate the correlations of the $G C V$ measurement starting with the element composition and the ash content. On the remaining data - database for application $\left(D B_{a}\right)$ - the models were tested on their performance. This criterion of management of the database allows to return a first evaluation on the forecast ability of the models. More in detail the measure of this ability is linked from parameters that measure the difference among the expected data from the model and the real data.

In every database, descriptive statistics were carried out to calculate the mean, the standard deviation $(S D)$, the coefficient of variability $(C V)$ and the maximum and minimum median for every parameter. The development of the models to calculate the $G C V$ was conducted through the application of the regression analysis on the $D B_{c}$ data. Statistical analysis has considered all the possible resultant models from the combination of all the variables. The best obtained correlations, chosen on the basis of the values of the $\mathrm{R}^{2}$, were tested on the contents of the data in the $D B_{a}$. The same method was applied on the mathematical correlations identified in the bibliography and applied on solid biomasses. The latter are shown in Table 2 , in which $C, H, N, O$ and $S$ represent the percentage content on dry basis of carbon, hydrogen, nitrogen, oxygen and sulphur respectively. All the statistical analysis of this work was conducted with the software MINITAB $®$ Release 14 . The criteria used to evaluate the performance of the various correlations was based on the calculation of the average absolute error $(A A E)$ and average bias error $(A B E)$ computed as follows [Friedl 2005; Demirbas 1997]:

$$
\begin{aligned}
& A A E=\frac{1}{n} \sum_{i=1}^{n}\left|\frac{G C V_{c}-G C V_{w}}{G C V_{n}}\right| \cdot 100 \\
& A B E=\frac{1}{n} \sum_{i=1}^{n}\left(\frac{G C V_{c}-G C V_{n}}{G C V_{n}}\right) \cdot 100
\end{aligned}
$$

in which $G C V_{c}$ is the calculated gross calorific value dry basis while $G C V_{m}$ is the measured gross calorific value dry basis and $n$ is the number of all samples. The mathematical correlations marked by absolute values that are lower than $A A E$ and $A B E$ 


\begin{tabular}{|c|c|c|c|}
\hline Analysis & Normative & Apparatus & Precision \\
\hline$A_{C}$ & CEN/TS 14775 & Electric muffle furnace & $\pm 0.1 \%$ \\
\hline$G C V$ & CEN/TS 14918 & Isoperibolic bomb calorimeter - IKA 2000 & $\pm 4.18 \mathrm{~kJ}$ \\
\hline$N C V$ & CEN/TS 14918 & Method of measurement & $\pm 4.18 \mathrm{~kJ}$ \\
\hline Element analysis & CEN/TS 15104 & Perkin Elmer - Calculation of percentage content of & C, H, N, O, S \\
\hline
\end{tabular}

TABLE $1-$ Technical normative considered for the execution of analysis.

\begin{tabular}{|c|l|l|c|}
\hline Number & \multicolumn{1}{|c|}{ Model } & \multicolumn{1}{|c|}{ Author } & Unit \\
\hline 1 & $G C V=1.87 C^{2}-1.44 C-2820 H+63.8 C \cdot H+129 N+20147$ & Friedl, 2005 & $\mathrm{kJ} / \mathrm{kg}$ \\
\hline 2 & $G C V=5.22 C^{2}-319 C-1647 H+38.6 C \cdot H+133 N+21028$ & Friedl, 2005 & $\mathrm{kJ} / \mathrm{kg}$ \\
\hline 3 & $G C V=3.55 C^{2}-232 C-2230 H+51.2 C \cdot H+131 N+20600$ & Friedl, 2005 & $\mathrm{kJ} / \mathrm{kg}$ \\
\hline 4 & $G C V=491.2 C-911 H+117.7 O$ & Thipkhunthod, 2005 & $\mathrm{MJ} / \mathrm{kg}$ \\
\hline 5 & $G C V=430.2 C-186.7 H-127.4 N+178.6 S+184.2 O-2379.9$ & Thipkhunthod, 2005 & $\mathrm{MJ} / \mathrm{kg}$ \\
\hline 6 & $G C V=-1.3675+0.3137 C+0.7009 H+0.0318 O$ & Sheng, 2005 & $\mathrm{MJ} / \mathrm{kg}$ \\
\hline
\end{tabular}

TABLE $\quad 2$ - Models chosen from literature (all the parameters are on dry basis).

were considered to be the most suitable for the calculation of $G C V$.

An important part of the research has been devoted to the development of a mathematical relationship for the simplified determination of the $N C V$ through the measure of $C$. On the base of (3) it is possible to calculate $N C V$ beginning from $G C V$ and from the knowledge of the element composition [CEN/TS 14918:2005].

$$
N C V=G C V-212.2 H-0.8(O+N)
$$

If such equation is applied to a typical composition of lignocellulosic biomass $(H=6 \% ; O=39 \%$ e $S=$ $0,1 \%)$ it is observed that $H$ influence more than other two elements. It is possible to deduct how the energetic contribution of hydrogen, when calculating $N C V$, has a weight of over 30 times greater than that from the other two elements. Additionally the existence of a bond between $H$ and $C$ is presumable. In this way $C$, when implemented in mathematical models, it could be considered representative of $H$.

In particular, on this aspect an analysis of the distribution of the relationship has been conducted among $C$ and $H(C / H)$ for the different material considered in $D B_{c}$ dividing them in classes of origin (Table 3). With the purpose to underline some differences among the various groups of materials an analysis ANOVA one-way, test di Tukey 95\%, it has been conducted.

Similar to $G C V$, for $N C V$ the criteria used for the evaluation of the correlation performance is based on the calculation of $A A E$ (4) and $A B E(5)$. In particular:

$$
\begin{aligned}
& A A E=\frac{1}{n} \sum_{i=1}^{\pi}\left|\frac{N C V_{s}-N C V_{w}}{N C V_{v}}\right| \cdot 100 \\
& A B E=\frac{1}{n} \sum_{i=1}^{n}\left(\frac{N C V_{c}-N C V_{n}}{N C V_{w}}\right) \cdot 100
\end{aligned}
$$

in which $N C V_{c}$ is the calculated net calorific value dry basis while $N C V_{m}$ is the net calorific value dry basis measured with the appropriate method and $n$ is the number of all samples.

\section{Results}

Tables 4 and 5 include the main descriptive statistical parameters of the two databases used for this study.

On the whole, the characteristics of the samples from the two databases are very similar, especially for the value of $G C V$ and of $C$ and $H$. Some differences were only registered for the $A_{C}$ and $N$ values. Table 6 contains the results of the regression analysis developed on $D B_{c}$. The mathematical correlations obtained and the relative $\mathrm{R}^{2}$ values are given in detail. It can be noticed that all the correlations present $\mathrm{R}^{2}$ values between 0.7 and 0.8 , higher even if to a small extent, for the more variable correlations. It is possible to note that the simple correlation, equation 10 , that links the

\begin{tabular}{|c|c|}
\hline Biomass class & Samples $(n)$ \\
\hline Forestal & 84 \\
\hline Arboreous & 7 \\
\hline Agro-industrial & 34 \\
\hline Herbaceous & 17 \\
\hline Nuts & 16 \\
\hline Faecal matter & 7 \\
\hline Seeds and oilcake & 35 \\
\hline
\end{tabular}

TABLE 3 - Composition of the $D B_{c}$ according to the classes of origin. 
$G C V$ only to $C$, presents $\mathrm{R}^{2}$ value that is a little lower than that of more complex correlations, i.e. equation 9 and 11 , containing 5 and 4 variables, respectively to be used for in the calculation. The performance test of the correlations recorded in Table 2 and Table 6, applied to 251 data from the $D B_{a}$, is represented by the $A A E$ and $A B E$ values reported in Table 7. Except for equations 5 and 6 , the results show $A A E$ values of less than $3.3 \%$ and $A B E$ values between $-1.95 \%$ and $0.85 \%$. The general observation is that, on average, the equations underestimate the $G C V$ value compared to the real one.

\begin{tabular}{|c|c|c|c|c|c|c|c|}
\hline Element & Unit & Average & SD & CV & Min & Median & Max \\
\hline$C$ & $\%$ & 48.4 & 4.4 & 9.0 & 23.6 & 49.2 & 60.2 \\
\hline$H$ & $\%$ & 6.1 & 0.5 & 8.2 & 2.7 & 6.1 & 7.6 \\
\hline$N$ & $\%$ & 1.2 & 1.5 & 116.3 & 0.0 & 0.7 & 8.0 \\
\hline$O$ & $\%$ & 38.8 & 6.6 & 17.0 & 9.9 & 41.1 & 46.2 \\
\hline$S$ & $\%$ & 0.1 & 0.2 & 171.3 & 0.0 & $<0.1$ & 1.0 \\
\hline$A_{C}$ & $\%$ & 5.3 & 8.4 & 159.4 & 0.1 & 1.9 & 49.7 \\
\hline$G C V$ & $\mathrm{~kJ} / \mathrm{kg}$ & 19134 & 2064 & 10.8 & 10800 & 19205 & 27330 \\
\hline
\end{tabular}

TABLE 4 - Descriptive statistic of $D B_{c}$.

\begin{tabular}{|c|c|c|c|c|c|c|c|}
\hline Element & Unit & Average & SD & CV & Min & Median & Max \\
\hline$C$ & $\%$ & 47.7 & 3.3 & 7.0 & 24.3 & 48.4 & 52.3 \\
\hline$H$ & $\%$ & 6.2 & 0.6 & 10.6 & 3.3 & 6.3 & 8.8 \\
\hline$N$ & $\%$ & 0.8 & 0.6 & 81.5 & 0.2 & 0.6 & 4.7 \\
\hline$O$ & $\%$ & 39.4 & 4.4 & 11.3 & 17.6 & 40.3 & 63.2 \\
\hline$S$ & $\%$ & 0.1 & $<0.1$ & 121.2 & 0.0 & $<0.1$ & 0.5 \\
\hline$A_{C}$ & $\%$ & 6.1 & 5.0 & 81.8 & 0.3 & 4.4 & 28.3 \\
\hline$G C V$ & $\mathrm{~kJ} / \mathrm{kg}$ & 18946 & 1193 & 6.3 & 13065 & 19247 & 23015 \\
\hline
\end{tabular}

TABLE 5 - Descriptive statistic of $D B_{a}$.

Among the relations taken from bibliography, equation 2 shows better $A A E$ and $A B E$ values, $2.66 \%$ and $-0.20 \%$ respectively. Similar results were obtained with equation 10 that seems to be the best among those found from the data of this study. In the graph of Figure. 1 there are the values of $C$ with respect to $H$. Indeed it shows the presence of a positive relationship between the two elements though with a

\begin{tabular}{|c|c|c|c|}
\hline Equation & $A B E$ & $A A E$ & Reference \\
\hline & $(\%)$ & $(\%)$ & \\
\hline 1 & 0.69 & 2.73 & Friedl, 2005 \\
\hline 2 & -0.20 & 2.66 & Friedl, 2005 \\
\hline 3 & -0.62 & 3.12 & Friedl, 2005 \\
\hline 4 & 0.79 & 2.75 & Thipkhunthod, 2005 \\
\hline 5 & 18.99 & 19.09 & Thipkhunthod, 2005 \\
\hline 6 & 27.65 & 27.65 & Sheng, 2005 \\
\hline 7 & 0.85 & 3.27 & Current author \\
\hline 8 & -0.89 & 2.94 & Current author \\
\hline 9 & -1.95 & 3.06 & Current author \\
\hline 10 & -0.27 & 2.80 & Current author \\
\hline 11 & -1.93 & 3.05 & Current author \\
\hline
\end{tabular}

TABLE $7-A B E$ and $A A E$ values relative to the various empirical correlations for the calculation of $G C V$.

low correlation that has $\mathrm{R}^{2}$ of 0.49 . Anyway, the biomasses with high $\mathrm{C}$ potentially contains in average a greater value of $\mathrm{H}$.

When considering a typical composition of lignocelluloses biomass with carbon content between $45 \%$ and $55 \%$, an average $C / H$ value between 7.2 and 8.1 is observed (Table 8).

Nevertheless, the analysis of the $\mathrm{C} / \mathrm{H}$ value for the various biomass classes, as defined in Table 3 , shows some differences. Table 8 contains the average values of $\mathrm{C} / \mathrm{H}$ for every biomass.

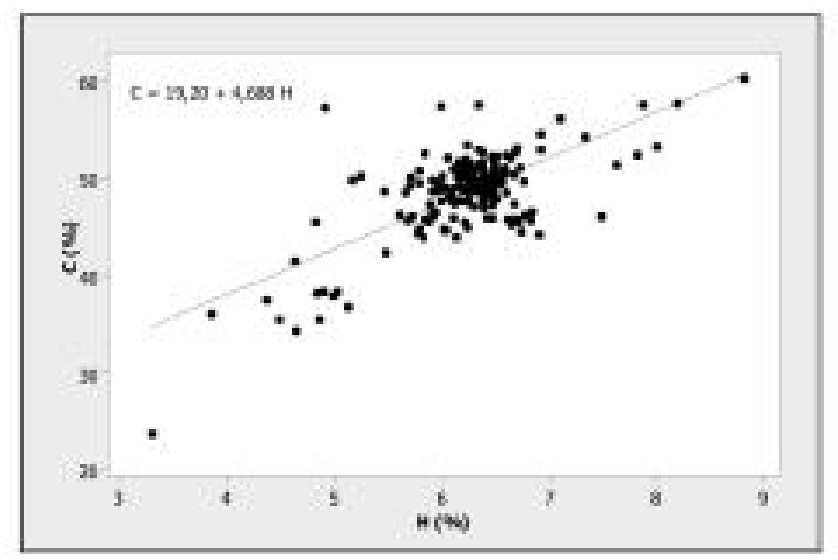

Fig. 1 - Relationship between $C$ and $H$ for different samples.

\begin{tabular}{|c|l|c|c|}
\hline Number & \multicolumn{1}{|c|}{ Typology } & $\mathrm{R}^{2}$ & Unit \\
\hline 7 & $G C V=971+323,6 C+711 H$ & 0.754 & $\mathrm{~kJ} / \mathrm{kg}$ \\
\hline 8 & $G C V=-2494+379,3 C+468,8 H+292,6 N$ & 0.772 & $\mathrm{~kJ} / \mathrm{kg}$ \\
\hline 9 & $G C V=-4311+401,1 C+294,3 H+340,7 N+42,3 O+298 S$ & 0.783 & $\mathrm{~kJ} / \mathrm{kg}$ \\
\hline 10 & $G C V=297,6+389,7 C$ & 0.728 & $\mathrm{~kJ} / \mathrm{kg}$ \\
\hline 11 & $G C V=-79,5+358,7 C+252 H+298,5 N+1201 S-177,1 A_{C}$ & 0.783 & $\mathrm{~kJ} / \mathrm{kg}$ \\
\hline
\end{tabular}

TABLE 6 - List of correlations tested for the development of model and $\mathrm{R}^{2}$ value. 


\begin{tabular}{|c|c|c|}
\hline \multirow{2}{*}{ Biomass } & \multicolumn{2}{|c|}{$C / H$} \\
\cline { 2 - 3 } & Average & $S D$ \\
\hline Forestal & 7.93 & 0.48 \\
\hline Arboreous & 7.67 & 0.25 \\
\hline Agro-industrial & 7.85 & 0.49 \\
\hline Herbaceous & 8.40 & 0.88 \\
\hline Nuts & 8.24 & 1.35 \\
\hline Animal dejections & 7.31 & 0.22 \\
\hline Seeds and oilcake & 7.19 & 0.65 \\
\hline
\end{tabular}

TABLE $\quad 8-$ Average values and $S D$ of functioning $C / H$ for the various biomass classes.

It is interesting to observe the differences of the $\mathrm{C} / \mathrm{H}$ value in various groups of the biomass class. Specifically, the arboreous, forest and the agro-industrial classes have an intermediate $C / H$ value between 7.7 and 7.9 (group A), unlike the herbaceous and nut classes with a $C / H$ value of 8.2 and 8.4 (group B). Then follows a third group of products made up of animal dejections, seeds and oilcake for extraction (group C) with average $C / H$ values between 7.2 and 7.3.

Results from ANOVA one-way test (Table 9), have put in evidence significant difference among the three groups $(p<0,001$ and $F$ statistic $=18,28)$. Finally, the graph of Figure 2 shows the relation that links the $N C V$ with the $C$.

The correlation that has $\mathrm{R}^{2}$ value of 0.715 , has shown high performance in the test with the $D B_{a}$ with $A B E$ and $A A E$ values of $0.28 \%$ and $3.99 \%$, respectively.

\begin{tabular}{|c|c|c|c|}
\hline $\begin{array}{c}\text { Tukey } \\
\text { contrast }\end{array}$ & Difference & $95 \%$ CI & Note \\
\hline C vs A & -0.430 & -0.811 to -0.048 & Significant \\
C vs B & 0.683 & 0.336 to 1.026 & Significant \\
A vs B & 1.111 & 0.657 to 1.563 & Significant \\
\hline
\end{tabular}

TABLE 9 - Results from ANOVA one-way applied on different biomasses groups.

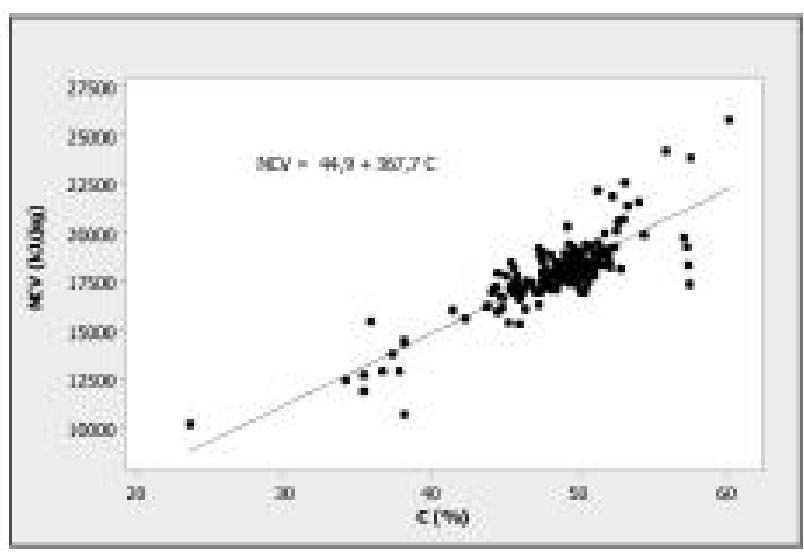

Fig. 2 - Correlation between $N C V$ and $C$.

\section{Considerations}

A simple and economic calculation of the energetic content of the biomasses can be affected by using the specific mathematical correlations that link $G C V$ with the basic composition. The correlations tested in this work highlight how this objective can be reached with $A B E$ and $A A E$, lower than the absolute $2.0 \%$ and $3.2 \%$, respectively. For generic biomasses, such as those analyzed by the author, there will be average errors lower than $630 \mathrm{~kJ} / \mathrm{kg}$ which will go down to less than $500 \mathrm{~kJ} / \mathrm{kg}$ for the most performing mathematical correlations. The latter data is about 4 times the limit of repeatability provided for in CEN/TS 14918 "Solid Biofuels - Method for the determination of calorific value" and corresponds to the effect that it will have on the estimation of the energetic content of the biomass, deriving from an error on the humidity content between about $2 \%$ and $3 \%$ included. Such result appears important in relationship to the aim proposed regarding the simplified determination of the $G C V$.

Nevertheless, not all the correlations present in literature, even if marked by good statistical parameters (equations 5 and 6), can produce satisfying estimations. It is possible to hypothesize how this type of biomass, originating from the data on which these models were developed, presents various characteristics producing mathematical relations which does describe the behaviour of the various material well. The importance of the errors of measurement must also be added. It is significant in the case of mathematical correlations produced with data from bibliographical sources (sometimes different) and not from measurements obtained with standard analytic methods. Both the calculation of $G C V$ with calorimetric cylinder and that of the element composition, involve weighing for the biomass quantity with high precision and the continuous calibration of the tools that can condition the quality of the data.

The study also shows that the simple correlations have performances that can be compared with those of more complex ones. Among these, correlation 10 which links $G C V$ to the only carbon content, which has shown an $A A E$ value of about $2.8 \%$. The observation that the carbon content is partly representative of the hydrogen content, which affects the $N C V$ calculation in a preponderant manner, could justify the good correlation that it has with the latter parameter. This correlation, whose $A A E$ was found to be less than $4 \%$, calculated on real $N C V$ data, can be an important possibility for the simplification of material analysis, above all in those operative contexts, like a power plant, in which the monitoring of the energetic content of the biomass is intense. The improvement of these models and the predisposition of the carbon and humidity analyzers operating continuously or semicontinuously on conveyor belts may open the possibility to develop systems for the calculation of the biomass energetic content in big energetic plants al- 
lowing more frequent monitoring in shorter time with consequent benefits in economic terms and reduction analysis time.

\section{References}

Obernberger I., Brunner T., Barnthaler G., 2006. Chemical properties of solid biofuels-significance and impact. Biomass and Bioenergy, 30, 973-982.

Fernandez Llorente M.J., Carrasco Garcia J.E., 2008. Suitability of thermo-chemical corrections for determining gross calorific value in biomass. Thermochimica Acta, 468, 101-107.

CEN/TS 14918: 2005 - Solid Biofuels - Method for the determination of calorific value.

Meraza L., Oropeza M., Dominguez A., 2002. Prediction of the Combustion Enthalpy of Municipal Solid Waste. Chem. Educator, 7, 66-70.

Meraza L., Dominguez A., Kornhauserb I., Rojas F., 2003. A thermochemical concept-based equation to estimate waste combustion enthalpy from elemental composition. Fuel, 82, 1499-1507.

Sheng C., Azevedo J.L.T, 2005. Estimating the higher heating value of biomass fuels from basic analysis data. Biomass and Bioenergy, 28, 499-507.

GHARAGHEIZ F., 2008. A simple equation for prediction of net heat of combustion of pure chemicals. Chemometrics and Intelligent Laboratory Systems, 91, 177-180.

Friedl A., Padouvas E., Rotter H., Varmuza K., 2005. Prediction of heating values of biomass fuel from elemental composition. Analytica Chimica Acta. 544, 191198.

Thipkhunthoda P., Meeyoob V., Rangsunvigita P., KITIYANANA B., Siemanonda K., RIRKSOMBOON T., 2005. Predicting the heating value of sewage sludges in Thailand from proximate and ultimate analyses, Fuel. 84, 849-857.

Demirbas A., 1997. Calculation of higher heating values of biomass fuels, Fuel, 76, 431-434.

Parikha J., Channiwalab S.A., Ghosalc G.K., 2005. A correlation for calculating HHV from proximate analysis of solid fuels. Fuel 84, 487-494.

Channiwala S.A., Parikh P.P., 2002. A unified correlation for estimating HHV of solid, liquid and gaseous fuel. Fuel, 81, 1051-1063.

Giordano G., Tecnologia del Legno 1. UTET, 1971, Torino, pagg. 1086.

Demirbas A., 2001. Relationships between lignin contents and heating values of biomass. Energy Conversion \& Management, 42, 183-188.

CEN/TS 14775: 2004 - Solid biofuels - Method for the determination of ash content.
CEN/TS 15104: 2005 - Solid biofuels - Determination of total content of carbon, hydrogen and nitrogen - Instrumental methods.

CEN/TS 14780 - Solid biofuels - Methods for sample preparation.

\section{SUMMARY}

The gross calorific value $(G C V)$ and, in particular, the net calorific value $(N C V)$ are fundamental physical parameters in the use of energetic biomass. The method of measurement and the calculation of the $G C V$, defined by CEN/TS 14918, is rather complex and, in many cases, has a time and cost importance. In literature there are some studies in which the empirical correlations between $G C V$ and the element composition have been calculated. In these contribution some of the most significant correlations in literature are tested and compared to others obtained from statistical processing of data from analysis on 200 samples of biomass carried out in the laboratory and with standard CEN methods. The study shows how the very simplified correlations based on the calculation of carbon and hydrogen content have performances that are similar to those of more complex ones based on the greater number of parameters. In particular, the empirical correlation $(G C V=297.6+389.7 C)$ produced from this work has errors that are comparable to those of the better correlation highlighted by literature $\left(G C V=5.22 C^{2}-319 C-1647 H+38.6 C \cdot H+133 N\right.$ $+21028)$.

Keywords: calorific value, estimating, solid biomass, elemental analysis, fuel.

\section{List of symbols}

$A A E \quad$ average absolute error (\%)

$A B E$ average bias error (\%)

$A_{C} \quad$ ash content (\%)

C carbon content $(\%)$

$\mathrm{C} / \mathrm{H}$ ratio carbon hydrogen

$C V \quad$ variability coefficient $(\%)$

$D B_{a} \quad$ database for application

$D B_{c}{ }^{a}$ database for calculation

$G C V$ gross calorific value $(\mathrm{kJ} / \mathrm{kg})$

$H \quad$ hydrogen content $(\%)$

$N \quad$ nitrogen content $(\%)$

$\mathrm{NCV}$ net calorific value $(\mathrm{kJ} / \mathrm{kg})$

$O \quad$ oxygen content $(\%)$

$S \quad$ sulfur content (\%)

SD standard deviation 